doi) https://doi.org/10.31977/grirfi.v21i3.2355

Recebido: 10/05/2021 | Aprovado: 11/09/2021

Received: 05/10/2021 | Approved: 09/11/2021

\title{
OS CAMINHOS DA TOLERÂNCIA
}

\author{
Jorge Alberto Ramos Sarmento ${ }^{1}$ \\ Universidade Federal do Pará (UFPA) \\ https://orcid.org/0000-0002-7969-0299 \\ E-mail: jars@ufpa.br
}

\section{RESUMO:}

O presente trabalho, elaborado a partir de um caráter teórico, bibliográfico e documental, tem por objetivo desenvolver algumas abordagens teóricas a respeito do conceito de tolerância de um ponto de vista filosófico, ao longo de um contexto histórico que se inicia no pensamento de John Locke, na Idade Moderna, no âmbito das guerras religiosas, quando tal conceito adquire um caráter mais rigoroso e crítico, indo até a contemporaneidade, período em que a tolerância passa a adquirir um papel de destaque para a compreensão dos sistemas políticos e das sociedades marcadas por um elevado grau de complexidade e pluralismo. Autores como Stuart Mill, Bobbio, Adorno e Habermas, entre outros, apresentam contribuições significativas a partir de suas reflexões e questionamentos para os estudos dessa temática assim como para o enfrentamento das patologias que afligem a contemporaneidade. Mais recentemente, o fato de a tolerância ter se transformado em consenso e marco normativo, através da elaboração e aprovação da Declaração Mundial dos Princípios da Tolerância, no ano de 1995, pela ONU, reflete a importância e o papel central que a tolerância exerce hoje na busca da paz e na construção de um mundo mais justo e humano.

PALAVRAS-CHAVE: Tolerância; Intolerância; Pensamento moderno; Pensamento contemporâneo.

\section{THE PATHS OF TOLERANCE}

\begin{abstract}
:
The present work, elaborated from a theoretical, bibliographical and documentary character, has for objective to develop some theoretical boardings regarding the concept of tolerance of a philosophical point of view, during a historical context that if initiates in the thought of John Locke, in the Modern Age, the scope of the religious wars, when such concept acquires a more rigorous and critical character, going until the contemporaneidade, period where the tolerance starts to acquire a paper of prominence for the understanding of the systems politicians and the societies marked for one raised degree of complexity and pluralism. Authors as Stuart Mill, Bobbio, Adorno and Habermas, among others, present significant contributions from its reflections and questionings for the studies of this thematic one as well as for the confrontation of the patologias that afflict the contemporaneidade. More recently, the fact of the tolerance to have if transformed into consensus and normative landmark, through the elaboration and approval of the World-wide Declaration of the Principles of the Tolerance, in the year of 1995, for the ONU, reflects the importance and the central paper that the tolerance exerts today in the search of the peace and the construction of a world more just and human being.
\end{abstract}

KEYWORDS: Tolerance; Intolerance; Modern thought; Contemporaneity thought.

\footnotetext{
${ }^{1}$ Doutor(a) em Ciências Sociais pela Universidade Federal do Pará (UFPA), Belém - PA, Brasil. Professor(a) da Universidade Federal do Pará (UFPA), Belém - PA, Brasil.
}

SARMENTO, Jorge Alberto Ramos. Os caminhos da tolerância. Griot : Revista de Filosofia, Amargosa - BA, v.21 n.3, p.390-407, outubro, 2021. 


\section{Introdução}

O conceito de tolerância, entendido geralmente como a capacidade de aceitar opiniões e comportamentos diferentes em nosso meio social, perpassa por um contexto histórico que se expressa em várias correntes filosóficas, as quais congregam tanto pensadores modernos quanto contemporâneos, tendo sido empregado preliminarmente nos litígios religiosos envolvendo católicos e protestantes. O pensador humanista Erasmo de Roterdã, em sua obra Elogio da Loucura, de 1509, desenvolve pesadas críticas às guerras e conflitos de sua época, retratando as intolerâncias religiosas e vendo como única solução possível para a transformação da Igreja a tolerância, muito embora não tenha procedido uma reflexão profunda sobre tal conceito, o qual adquire relevância na compreensão de temáticas que envolvem o pensamento político-jurídico e de forma mais restrita, os modelos democráticos com os quais convivemos atualmente. Nesse sentido, as reflexões sobre esse tema levam em conta uma recorrência histórica ao quadro das guerras de religião ocorridas na Europa, em particular na França do século XVI, quando, através das garantias do Estado se tornou possível uma tolerância provisória e orientada, que deu sustentação à coexistência de diferentes confissões, fato que teve repercussão considerável, em função de ter proporcionado novas perspectivas nas relações entre a Igreja e o Estado, estabelecendo as bases da tolerância civil, enquanto forma de resolução dos conflitos religiosos e que se efetivou através dos editos reais, considerados como a primeira forma de imposição estatal da tolerância.

Tais fatos se destacam num processo pelo qual a modernidade em seu amplo espectro de acontecimentos passa a gestar as condições necessárias para o surgimento de uma forma de tolerância, primordialmente vinculada às discussões na esfera religiosa, passando paulatinamente a encarnar os debates em torno da democracia tal como desenvolvidos por pensadores como John Locke, Voltaire e Kant, dentre outros, cujas contribuições teóricas foram essenciais para a percepção das questões éticas e políticas levantadas na época e que se tornaram base para o norteamento de um novo ideal civilizatório, tal como proposto por Kant ao estabelecer os princípios basilares do ideal iluminista, tido como projeto da modernidade, onde a "saída do homem de sua menoridade" reflete a necessidade de sua emancipação pelo uso da razão.

As reflexões suscitadas pelos pensadores contemporâneos sobre a tolerância desde Stuart Mill até Habermas manifestam a preocupação sobre as crises existentes em nossas sociedades, marcadas por um alto nível de pluralidade e complexidade. Habermas que em suas obras dedica especial destaque aos conceitos de "esfera pública" e "razão comunicativa", defende o valor da tolerância no contexto atual, o qual se encontra dominado por diversas formas de violência.

No referido trabalho a metodologia utilizada foi pautada em pesquisa bibliográfica, através de livros, artigos e periódicos, nos quais se discute a temática aqui apresentada, assim como uma pesquisa de caráter histórico explicativa, que de certa forma se enquadra nas ideias desenvolvidas.

\section{A tolerância no pensamento moderno}

A partir do século XVII, as reflexões de John Locke e Pierre Bayle trouxeram contribuições significativas para a formação do pensamento filosófico a respeito da tolerância. Pierre Bayle proporcionou, através de sua obra, uma grande contribuição para a construção do discurso filosófico sobre tal conceito, sendo seus escritos considerados essenciais para a disseminação dessa ideia pelos filósofos do século XVII, pressupondo uma tolerância de caráter amplo, num ressignificado do conceito de tolerância, a qual, anteriormente percebida como um vício, na 
medida em que tolerar estava relacionada ao sofrimento, a partir do século XVIII adquire o significado de virtude. Por seu turno, John Locke direciona sua concepção nas liberdades individuais, nas restrições ao poder coercitivo do Estado e na defesa da diversidade de opiniões, estabelecendo, de maneira geral, uma relação entre tolerância e liberdade de expressão. Voltaire a partir da ideia fundamentada na filiação divina, defende que todos os indivíduos são iguais, havendo, portanto, a necessidade do exercício da tolerância e a ajuda mútua para que se possa superar os desafios impostos pela existência. Na perspectiva de Kant, um dos filósofos mais importantes do Iluminismo, a tolerância integra um dos princípios do Projeto da Modernidade, na expressão de uma tendência de justificar e legitimar todas as formas de liberdade religiosa, assim como se contrapor a qualquer tipo de discurso que porventura possa sustentar a existência de intolerâncias.

\subsection{John Locke: tolerância e liberdade de expressão}

John Locke é considerado como o pensador moderno mais representativo na formulação desse conceito de tolerância, sendo o seu texto Carta acerca da tolerância, tido como basilar na demarcação entre as duas esferas da vida associativa, no caso a religião e a política, cujas ideias encontram-se plenamente em harmonia com o processo de laicização ora em andamento naquele momento na Europa. Logo no início da referida obra estabelece que "a tolerância para os defensores de opiniões opostas acerca de temas religiosos está tão de acordo com o Evangelho e com razão que parece monstruoso que os homens sejam cegos diante de luz tão clara" (LOCKE, 1983, p. 4).

Para o referido autor, a legitimidade da tolerância em relação as dissidências de opinião a respeito de questões religiosas devem se fundamentar em duas fontes: a doutrina cristã, considerada como paradigma da religião, e a razão, tendo em vista que tanto em matéria de crença religiosa como na busca do conhecimento racional e na defesa de seus pressupostos, torna-se necessário o predomínio da liberdade, tanto da vontade como do pensamento.

Ao poder civil, que possui a prerrogativa da coação, cabe o uso da força para manter a coesão social, o estabelecimento de leis uniformes, a preservação e a defesa de bens civis (constituídos pela vida, liberdade, saúde física, libertação da dor e propriedades de bens móveis e imóveis), enquanto ao poder religioso, que se encontra fundado na persuasão interior do espírito, cabe o "cuidado da alma". Nesse sentido, deve haver sempre uma separação ente Religião e Estado, tendo em vista que o primeiro traz adeptos para seu domínio pela persuasão, enquanto ao segundo cabe elaborar leis imparciais com vistas a punir aqueles que não a cumprem com a privação da liberdade ou dos bens. Tal fato ocorre em função de haver uma diferenciação entre ambos: à Religião não compete ordenar, mas convencer através de argumentos. Já o Estado, entendido como uma nação politicamente organizada, ordena e obriga através de decretos, possuindo também o monopólio da força. Locke enfatiza que a persuasão é a via capaz de levar ao esclarecimento, o qual nos conduz de forma sábia neste mundo, tornando-se um valioso instrumento capaz de nos guiar até o mundo espiritual. Em oposição, surgem as leis civis que possuem como prerrogativa a busca da ordem social através das leis e administração dos indivíduos neste mundo. Pode-se perceber, nesse sentido a demarcação lockeana entre poder civil e religião, a qual expressa o início do processo de historização e privatização da religião e de dessacralização do poder político, que irá configurar a secularização enquanto um complexo fenômeno sociopolítico e cultural característico da modernidade.

Enquanto elemento constitutivo do processo de secularização e voltada para a necessidade de regulação dos conflitos entre religião e política, a tolerância envolve a possibilidade de excluir do seio social e político tudo aquilo que se apresente como intolerável. Nesse sentido, Locke

SARMENTO, Jorge Alberto Ramos. Os caminhos da tolerância. Griot : Revista de Filosofia, Amargosa - BA, v.21 n.3, p.390-407, outubro, 2021. 
entende como tal "as doutrinas incompatíveis com a sociedade humana e contrária aos bons costumes e a preservação da sociedade civil" (Locke, 1983, p. 22).

Embora estabeleça uma completa separação entre Estado e Igreja, representativos dos poderes civil e religioso, a concepção de Locke (1983) compreende que a crença em Deus surge como princípio que legitima os pactos efetivados entre os indivíduos no contexto social e político, fato que parece contradizer com as visões baseadas no processo de laicização das sociedades daquela época. A defesa das liberdades individuais e de modo particular, da liberdade de expressão e de culto enquanto direito fundamental do indivíduo no estabelecimento de competências do poder eclesiástico e civil, constitui, pois, aspecto importante do pensamento desse autor, para quem "a comunidade é uma sociedade de homens constituída apenas para a preservação e melhoria dos bens civis de seus membros" (Locke, 1983, p. 23). Nesse ponto de vista, compreendese que o despojamento de bens e direitos, comuns em épocas passadas e aplicado a indivíduos que não professavam determinado credo constitui uma violação, visto que tais direitos (civis), não se confundem com o credo religioso.

\subsection{Voltaire: tolerância e sua relação com a ideia de igualdade}

No século das Luzes, a tolerância se torna um instrumento cada vez mais poderoso no combate aos interesses universalistas e dogmáticos da religião, e assim como Locke, destaca-se a figura de Voltaire como um dos mais importantes filósofos a se unir na luta contra os abusos dos poderes religiosos e políticos no cerceamento às liberdades em um período em que contraditoriamente Kant considera como a período em que o homem atingiu a maioridade, através do exercício da razão.

O Iluminismo é a saída do homem de sua menoridade, da qual ele próprio é culpado. A menoridade é a incapacidade de se servir do entendimento sem a orientação de outrem. Tal menoridade é por culpa própria se a sua causa não reside na falta de entendimento, mas na falta de decisão e de coragem em se servir de si mesmo sem a orientação de outrem. Sapere aude! Tem a coragem de te servires do teu próprio entendimento! Eis a palavra de ordem do Iluminismo. (KANT, 2018, p. 9, grifos do autor).

Voltaire elabora suas reflexões no Tratado sobre a tolerância tomando como referência um caso que se tornou emblemático na França: a injusta condenação à pena de morte em um julgamento popular, no ano de 1762, de Jean Calas, um protestante calvinista, sob a acusação de ter enforcado seu próprio filho, Marc Antoine, o qual supostamente pretendia se tornar católico. Diante de uma multidão histérica e enfurecida, e na ausência de provas materiais consistentes, Jean é condenado por oito dos treze conselheiros, numa clara demonstração do elevado nível da intolerância religiosa, capaz de se sobrepor aos próprios valores e princípios da justiça em um caso que apesar de sua ocorrência remota, nos leva ainda hoje a profundas reflexões. A esse respeito comenta Voltaire (2000, p. 13) “[...] era preferível supliciar um velho calvinista inocente a expor oito conselheiros $[\ldots]$ a admitirem que haviam se enganado".

Voltaire (2000) desenvolve pesadas críticas sobre um provável direito à intolerância reivindicado pelo poder religioso predominante, uma vez que, defender a intolerância significa, em última análise condenar todos aqueles que lutaram pela fé cristã desde as suas origens, sendo, portanto, incompreensível uma religião manter seu predomínio através do ódio. E caso se justificasse o direito à intolerância, haveria um momento em que todo o céu se encheria de criminosos, visto tanto mais seria um indivíduo considerado santo quanto mais hereges ele houvesse matado. No entendimento desse autor, a tolerância não pode ser ignorada pelo fato de 
produzir resultados positivos no convívio dos povos, e jamais ter sido a causa das guerras civis, diferentemente da intolerância que somente tem produzido resultados trágicos.

Enfim, essa tolerância jamais suscitou guerra civil, enquanto a intolerância cobriu a terra de chacinas. Que se julgue, pois entre essas duas rivais, entre a mãe que quer que matem seu filho e a mãe que o cede para que ele viva. (VOLTAIRE, 2000, p. 27).

Na obra Dicionário Filosófico, Voltaire apresenta uma definição sobre a tolerância marcada por uma série de críticas que se destacam pelo aspecto até certo ponto frio e calculista em que essa temática é tratada enquanto uma peculiaridade da natureza humana.

O que é tolerância? É o apanágio da humanidade. Somos todos cheios de fraquezas e de erros: perdoemo-nos reciprocamente tal é a primeira lei da natureza. [...] Devemos tolerarnos mutuamente porque somos todos fracos, inconsequentes, sujeitos a mutabilidade e ao erro. Um caniço que o vento verga sobre a lama, deverá dizer a outro caniço vergado em sentido contrário: 'Rasteja à minha maneira, miserável, ou apresento queixa de ti, para que te arranquem e queimem'(VOLTAIRE, 1984, p. 290).

Voltaire ressalta com toda veemência a condição degradante da natureza humana, a qual se destaca pela sua fraqueza, instabilidade e fragilidade, havendo a necessidade do perdão e da tolerância pelo fato de sermos todos fracos e, sobretudo, sujeitos ao erro, o que nos torna semelhante a "um caniço pensante" - numa referência a Pascal -, que não é capaz de aceitar as diferenças do outro, devendo este ser "arrancado" ou "queimado" se seus interesses colidirem com os nossos. Para o pensador em questão, é justamente num contexto da prática econômica que a virtude da tolerância melhor pode ser observada. Em outras palavras, a busca pelo lucro e pelo enriquecimento, consoante da atividade burguesa, a qual se encontra centrada num individualismo, que se estabelece um convívio no qual as diferenças deixam de existir.

Juntai na bolsa de Amsterdã, ou de Londres ou de Surate, ou do bossorá, o guebro, o baniano, o judeu, o maometano, o deícola chinês, o brâmane, o cristão grego, cristão romano, o cristão protestante, o cristão quacre, a traficarem entre si, e vereis que não levantarão o punhal uns contra os outros para ganharem almas à sua religião. (VOLTAIRE, 1984, p. 290).

\subsection{Kant: A tolerância como princípio do Projeto Iluminista}

Immanuel Kant, considerado um dos mais proeminentes pensadores do espírito iluminista, desenvolve uma concepção filosófica orientada a partir de um caráter universalista, com o propósito de estabelecer as condições necessárias capazes de dar suporte, tanto para a justificação quanto para a legitimação da liberdade religiosa, bem como para a eliminação de todo argumento racional utilizado para a legitimação de todas as formas de intolerância e perseguição religiosa. Ressalta-se que o próprio Kant, assim como muitos pensadores de sua época, também foi vítima da intolerância, a qual tanto combateu, quando da exposição de suas ideias na obra $A$ religião dentro dos limites da simples razão publicada em 1753, em função dela ter contrariado interesses religiosos e políticos predominantes naquele contexto histórico, ao procurar dar um tratamento racional à religião, desconsiderando a revelação divina tal como ela se apresenta nas Sagradas Escrituras. Na verdade, as reflexões que ocorrem no campo da filosofia moral têm ocasionado, desde tempos mais remotos até os dias atuais, problemas sérios e delicados que se refletem na intolerância e perseguição religiosa, em função principalmente da religião fundamentar uma determinada visão de mundo que se torna incompatível com outras visões.

SARMENTO, Jorge Alberto Ramos. Os caminhos da tolerância. Griot : Revista de Filosofia, Amargosa - BA, v.21 n.3, p.390-407, outubro, 2021. 
A filosofia universalista de Kant se destaca de forma clara na obra $\grave{A}$ paz perpétua, publicada em 1795 e escrita sob a forma de tratado, com grande influência na criação da ONU, sendo considerada até os dias atuais de importância capital para a percepção de uma política universal de direitos humanos, na qual o filósofo procura esclarecer a todos que exercem o poder nas nações sobre a necessidade da superação dos conflitos por uma ordem internacional nãoviolenta, cujos princípios devem estar assentados nas diretrizes da razão, onde a atividade filosófica se constitui um importante elemento para a edificação desse ideal, conforme o próprio Kant assinala:

Não é de esperar que reis filosofem ou filósofos tornem-se reis, mas também não é de se desejar, porque a posse do poder inevitavelmente corrompe o livre julgamento da razão. Porém, que reis ou povos reais (que governam a si mesmos segundo leis de igualdade) não minguem ou emudeçam a classe dos filósofos, mas deixem falar publicamente, é a ambos indispensável para iluminar sua ocupação, porque essa classe é incapaz, segundo sua natureza, de ajuntamentos e alianças de clubes, insuspeitos de uma propaganda por meio de boato. (KANT, 2018 p. 57 - grifos do autor).

A paz perpétua constitui uma meta a ser atingida através da tolerância, do respeito e do exercício de princípios e normas que se definem ao longo da obra.

De acordo com Klein (2015, p. 223), a tolerância para Kant pode ser compreendida como uma compassividade em relação àquilo que se considera um erro nos outros, enquanto a intolerância se refere ao indivíduo que não consegue suportar a imperfeição dos outros sem ódio e, nesse sentido, ele mesmo não pode ser suportado sem ódio. Nesse sentido, a tolerância se torna um dever universal de humanidade.

A liberdade individual constitui um dos valores mais caros do pensamento político e moral dos filósofos iluministas, evidenciando na expressão da liberdade de crença e na livre expressão de ideias o aspecto mais relevante de sua dimensão, a qual, para Kant é intrínseca da natureza humana e encontrando-se consolidada no imperativo categórico: "age de tal modo que a máxima da tua vontade possa valer sempre ao mesmo tempo como princípio de uma legislação universal" (Kant, 1995, p. 42), o que em outras palavras pode ser entendido como o fato de não desejar para o meu próximo aquilo que não desejaria para mim mesmo, expressando a necessidade de sermos tolerantes com os outros, na medida em que nas relações que estabelecemos existem limites que não podem ser ultrapassados, pouco importando o conteúdo das normas e das crenças. Conforme ressaltado pelo próprio Kant (1995), não devemos jamais considerar os seres humanos como meios, mas sempre como fim: "agora eu afirmo: o homem, e em geral todo ser racional, existe como fim em si mesmo, não só como meio para qualquer uso desta ou daquela vontade" (Kant, 1997, p. 76).

À guisa de esclarecimento, apesar dos grandes pensadores iluministas aqui citados terem adotado uma firme posição contra todas as formas de intolerância, observa-se que eles foram complacentes quanto à questão da intolerância racial, tendo alguns deles sustentado a ideia da superioridade da raça branca em relação à negra, em um contexto histórico predominantemente marcado pela escravização dos negros da África ${ }^{2}$. A esse respeito destaca-se o fato de Voltaire apesar de ter se destacado como defensor dos direitos humanos e contestado a escravidão na América, praticada pelas grandes potências de sua época, manteve silencio sobre a escravização promovida por seu país, tendo inclusive sido acusado de ter praticado o financiamento do tráfico

\footnotetext{
${ }_{2}^{2}$ A esse respeito vide a obra Escravidão de Laurentino Gomes, Ed. Globo, 2019, pp. 75-76 onde se destaca as afirmações de Locke, Voltaire e Kant sobre o tema.
} 
escravos e lucrado com esse fato ${ }^{3}$. Numa expressão sarcástica o referido pensador resume essa condição servil do ser humano: "[...] perguntai a um escravo se deseja ser franqueado e vereis o que vos responderá. Só por aí a questão já está decidida" (Voltaire, 1984, p. 167).

Em relação a Kant, observa-se em alguns de seus escritos um discurso que regra geral se alinha com o da maioria dos filósofos dos séculos XII e XVIII no que tange a um ideal de supremacia e de dominação dos europeus, considerados com os "condutores" do gênero humano, enquanto os habitantes das terras colonizadas (nativos), são considerados "selvagens", "incapazes de exercer a reflexão" e "preguiçosos", além de impossibilitados de atingirem a autonomia. Essa desigualdade entre o europeu civilizado e o nativo considerado selvagem é tida por Kant como um fato natural, cujo proposito visa o aperfeiçoamento da humanidade, em um processo em que os conflitos são parte integrantes.

Graças, pois, à Natureza pela incompatibilidade, pela vaidade invejosamente emuladora, pela ânsia insaciável de posses ou também do mandar! Sem elas, todas as excelentes disposições naturais da humanidade dormitariam eternamente, sem desabrochar. $\mathrm{O}$ homem quer concórdia; mas a natureza sabe melhor o que é bom para a sua espécie, e quer discórdia. Ele quer viver comodamente e na satisfação; a natureza, porém, quer que ele saia da indolência e da satisfação ociosa, que mergulhe no trabalho e nas contrariedades para, em contrapartida, encontrar também os meios de se livrar com sagacidade daquela situação. (KANT, 1990, p. 8-9).

Em outro texto, Kant aponta para alguns aspectos predominantes na raça negra tidos como fundamentos de sua inferioridade em relação ao europeu.

Aliás, o calor úmido é favorecedor do forte crescimento dos animais em geral, e breve, surge o Negro, que está bem adaptado ao seu clima, a saber, é forte, corpulento, ágil; mas, que, ao abrigo do rico suprimento da sua terra natal, [também] é indolente, mole e desocupado. (KANT, 2014, p. 21).

O projeto iluminista, tal como preconizado por Kant (2018) encontra-se fundado em princípios que possibilitam ao indivíduo se orientar pela sua própria razão, sem se deixar enganar pelas crenças religiosas, tradições e opiniões alheias. Nesse ponto de vista, o cerceamento às liberdades individuais, a opressão e a intolerância que se realizam na forma de guerras e perseguições se constituem como grandes entraves a esse projeto.

\section{Tolerância e contemporaneidade}

Marcadas pela complexidade e pluralidade, as sociedades do século XXI são resultantes de profundas transformações, as quais imprimiram novos valores e modelos de vida, refletindo como consequência uma visão de mundo voltada ao individualismo. A contemporaneidade é um período de aprofundamento dos conflitos e crises, que levaram pensadores desde Mill a Habermas, a apresentar uma visão sobre a tolerância não apenas voltada para a luta pela liberdade e igualdade, mas, principalmente pelo exercício do direito à diferença que se deve garantir aos diferentes, muito embora que as tentativas de implementação da tolerância, desconsiderando um aprofundamento sobre ela, tem contribuído para a instauração de práticas intolerantes em muitas sociedades.

\footnotetext{
${ }^{3}$ Conforme destacado por Couto Maia na obra Dicionário da escravidão negra no Brasil. Edusp, 2005.
} 


\subsection{Stuart Mill: A tolerância como resultante do livre mercado de ideias}

Seguindo uma linha de raciocínio da ética da liberdade com bases ancoradas no utilitarismo, doutrina que pressupõe uma ética consequencialista, na medida em que considera o valor de uma ação como dependente de suas consequências e com formulações que se contrapõem a Kant, John Stuart Mill (2000), desenvolve algumas reflexões relevantes a respeito da tolerância. Para Mill a tolerância tem sua origem a partir do momento em que existe a necessidade da supressão dos conflitos teológicos. Sendo a intolerância algo naturalmente humano.

A intolerância é tão natural ao homem em tudo quanto de fato lhe interessa, que na prática possivelmente a liberdade religiosa não se tenha concretizado em lugar algum, excerto onde a interferência religiosa, que detesta ver sua paz perturbada por conflitos teológicos, fez pender a balança a seu favor. (MILL, 2000, p. 15).

Mill (2000) é considerado um dos precursores na criação do Estado liberal, e ao longo de sua obra procura mostrar como a ideia de tolerância é tomada em sentido de limitação da liberdade individual, quando do emprego do termo pelos cristãos.

A tolerância foi a grande pedra fundamental das liberdades religiosas deste país (a Inglaterra) mas que ninguém abuse da preciosa palavra "tolerância". Conforme a compreendo, significa a completa liberdade a tudo, liberdade de culto entre cristãos que cultuarem com base no mesmo princípio. Significa tolerância a todas as seitas e denominações de cristãos que acreditam numa única mediação (citação de um discurso de um subsecretário de Estado em 12 de novembro de 1857). Quero chamar a atenção para o fato de um homem a quem se reputa capaz de ocupar um alto cargo no governo deste país sob um ministério liberal, defender a doutrina segundo a qual todos os que não acreditam na divindade de Cristo ficam fora do âmbito da tolerância. Quem, após essa manifestação imbecil, pode abandonar-se à ilusão de que a perseguição religiosa acabou para nunca mais voltar? (MILL, 2000, p. 49-50).

Num mundo marcado pela desigualdade social, violência e todas as formas de opressão, reflexo da grande crise social, haveria uma forma de se evitar a intolerância? Na visão de Stuart Mill tal resposta estaria vinculada ao "hábito de corrigir e completar a própria opinião, cotejandoa com a dos outros, longe de gerar dúvidas e hesitações ao pô-la em prática, constitui o único fundamento estável para que nela se tenha justa confiança" (Mill, 2000, p. 34). Tal argumento tem como princípio basilar a necessidade de que as decisões e atitudes de uma sociedade sejam submetidas a constantes discussões, no sentido de garantir legitimidade e responsabilidade a esse processo, evitando-se, dessa forma atitudes dogmáticas que não sejam oriundas de um consenso.

Mill (2000) entende que o conceito de tolerância se encontra articulado com a ideia de liberdade e de justiça, as quais, na medida em que passam a se estabelecer de forma dogmática, conduzem a uma dimensão de leis e sanções ilegítimas em função de terem sido derivadas de conceitos de liberdade e justiça erroneamente definidos. Daí a necessidade de se instituir determinados procedimentos democráticos como o debate e a reflexão pública, enquanto mecanismos de cunho hermenêutico, que propiciem à sociedade a existência dessas incoerências.

Em linhas gerais, o pensamento de Mill reflete a ideia de que somente em um "mercado livre de ideias", ou em outras palavras, em um contexto onde seja possível a convivência de diversas visões de mundo, conflitantes ao mesmo tempo, tornaria possível uma sociedade acabar com os preconceitos e atingir um nível mais elevado de conhecimento da verdade. 


\subsection{Theodor Adorno: intolerância e retorno à barbárie}

Theodor Adorno, filósofo integrante da Escola de Frankfut, cujo pensamento se destaca pela crítica radical ao modelo de capitalismo predatório das sociedades ocidentais, que traz consigo a mercantilização dos bens simbólicos através da chamada indústria cultural, procede uma análise sobre a forma pela qual a razão passa a se contrapor ao processo civilizatório, que foi cultivado pelo Iluminismo, trazendo como consequência a barbárie, representativa de um progresso irreparável.

Entendo por barbárie [...] que, estando na civilização do mais alto desenvolvimento tecnológico, as pessoas se encontrem atrasadas de um modo particularmente disforme em relação a sua própria civilização [...] por se encontrarem tomadas por uma agressividade primitiva, um ódio primitivo [...] um impulso de destruição, que contribui para aumentar ainda mais o perigo de que toda esta civilização venha a explodir, aliás uma tendência imanente que a caracteriza. (ADORNO, 2011, p. 155).

Em seus escritos, Adorno (2011) aponta para a exigência que a experiência de Auschwitz não se repita como condição para a existência de todas as formas de educação, o que nos leva a necessidade de repensar sobre o futuro de nossa civilização em um momento marcado por uma "agressividade primitiva" e um impulso de destruição que se expressa de forma institucionalizada na atualidade, potencializando a intolerância e traçando as bases de uma autodestruição global.

Passados 76 anos do terrível holocausto que vitimou milhões de judeus, observamos o retorno ao discurso do ódio, assim como o recrudescimento dos atos de intolerância contra as minorias, inclusive com o apelo ao ideário do regime nazista alemão.

\subsection{Karl Popper e os limites da tolerância}

Karl Popper, filósofo austríaco do século XX parte do pressuposto de que a tolerância em uma sociedade que adote uma política democrática, traz consigo avanços nas práticas científicas, possibilitando a aproximação de um conhecimento verdadeiro, no caso, o progresso social pois “[...] somente em uma sociedade aberta, em uma sociedade capaz de tolerar e respeitar muitas concepções e pontos de vista, podemos esperar aprender com nossos erros e, assim, nos aproximarmos da verdade" (POPPER, 2014, p. 306).

A importância da tolerância no âmbito político se torna importante para Popper (2014) na medida em que proporciona, em uma democracia, as melhores condições de vida aos indivíduos, desde que esteja compromissada em defender as instituições e o próprio princípio da tolerância para com todos os que compartilham do mesmo propósito.

Tomando por base as reflexões desenvolvidas por Voltaire, Popper conclui que a ideia de tolerância estabelece seus limites na intolerância, afirmando que tolerar tudo se torna algo perigoso, em virtude do fato de que tal decisão possibilita a destruição da liberdade e, por conseguinte, da própria tolerância.

O fundamento de Voltaire para a tolerância é que perdoemos uns aos outros nossas loucuras. Mas Voltaire, com razão, acha difícil tolerar uma loucura muito difundida, a da intolerância. De fato, a tolerância encontra aqui seus limites. Se concedermos à intolerância o direito de ser tolerada, destruímos a tolerância e o Estado de direito (POPPER, 2006, p. 245). 
Ao abordar a questão relacionada às sociedades democráticas, denominadas de sociedades abertas, Popper (2014) levanta a problemática referente aos limites de uma atitude tolerante, ou seja, de uma tolerância ilimitada. Para o referido autor, em função do temor dos indivíduos pela intolerância, eles optam por se tornarem tolerantes, mesmo com aqueles que não o são.

[...] com medo de ser intolerantes, estamos inclinados a estender a tolerância, como um direito, também àqueles que são intolerantes; ideologias que supõem o princípio de que todo mundo que sente nelas deve ser suprimido pela força; ideologias que passam a considerar todos os dissidentes até criminosos. Este é, em minha opinião, um dos nossos problemas mais sérios, não tanto do ponto de vista teórico, mas do ponto de vista prático. $\mathrm{E}$ isso me leva a afirmar que, em nossa lealdade à ideia de tolerância, corremos o risco de destruir a liberdade e, com ela, a tolerância. (POPPER, 2014, p. 389).

No ponto de vista acima destacado, Popper deduz que o fato de tolerar os outros de maneira ilimitada acarretaria uma contradição, consubstanciada no paradoxo da tolerância, o qual poderia levar à destruição de todos aqueles que a defendem, isto é “[...] se não estivermos preparados para defender uma sociedade tolerante contra os ataques dos intolerantes, o resultado será a destruição dos tolerantes" (Popper, 1974, p. 289).

\subsection{Norberto Bobbio e as razões da tolerância}

As contribuições do pensador Norberto Bobbio foram de fundamental importância para o aprofundamento da temática em questão. Bobbio, na obra $A$ era dos direitos (1992) discute a questão da tolerância no estudo denominado "As razões da tolerância" a partir do qual procura mostrar as dificuldades existentes ao se trabalhar com o referido conceito.

Inicio com uma consideração sobre o próprio conceito de tolerância e sobre o diferente uso que dele se pode fazer em diferentes contextos. Essa premissa é necessária porque a tolerância cujas "razões" pretendo analisar corresponde a apenas um dos seus significados, ainda que seja o historicamente predominante. Quando se fala de tolerância nesse seu significado histórico predominante, o que se tem em mente é o problema da convivência de crenças (primeiro religiosas, depois também políticas) diversas. Hoje, o conceito de tolerância é generalizado para o problema da convivência das minorias étnicas, lingüísticas, raciais, para os que são chamados geralmente de "diferentes", como, por exemplo, os homossexuais, os loucos ou os deficientes. (BOBBIO, 2004, p. 86).

Bobbio procede uma comparação da tolerância com a intolerância, a partir da qual deduz que o tolerante passa a ver o intolerante como fanático, acusando-o de ser cético ou indiferente se levasse em conta não existir uma verdade pela qual pudesse valer a pena lutar. Tal argumentação é refutada pelo autor que afirma que a relação intolerância-tolerância não pode ser correspondente à relação fanatismo-indiferença, na medida em que esta fundamenta sua formação numa oposição. É a partir desse ponto de vista que

Bobbio passa a apresentar algumas razões a respeito da tolerância.

Começo pela razão de prudência política: a tolerância como mal menor. Entendida desse modo, a tolerância implica a opinião de que a verdade tem tudo a ganhar quando suporta a erro alheio.

Essa razão assume diversos aspectos conforme a diferente natureza das correlações de forças, entre mim ou minha doutrina detentora da verdade e os outros, imersos no erro. (BOBBIO, 2004, p. 86). 
A respeito dessa razão, Bobbio esclarece que temos uma tendência em aceitar o erro alheio se somos a parte mais forte, por uma questão de astúcia pois a perseguição causa escândalo e isso faz crescer a mancha, que deve ser mantida oculta. E se somos a parte mais fraca, suportar o erro alheio é um estado de necessidade, visto que a rebelião implica no esmagamento e perda de qualquer esperança em relação ao futuro. No caso de sermos iguais o que entra em jogo é o princípio da reciprocidade a partir do qual se me atribuo o direito de perseguir os outros, também a eles concedo o direito de me perseguirem. Nos casos citados, a tolerância passa a ser o resultante de um cálculo, não se relacionando em nada com a questão da verdade.

A segunda boa razão encontra-se relacionada com um método universal de convivência civil, tendo como princípio basilar a utilização da persuasão, que diferentemente de métodos coercitivos, leva em conta a capacidade de entendimento e convencimento do outro sem a utilização do recurso à força como via para obter o triunfo das próprias ideias.

Subindo na escala das boas razões, passamos para a escolha de um autêntico método universal: a tolerância pode significar a escolha do método da persuasão em vez do método da força ou da coerção. Por trás da tolerância entendida desse modo, há uma concepção do homem como capaz de considerar seu próprio interesse à luz do interesse dos outros, bem como da recusa consciente da violência como único meio para obter o triunfo das próprias ideias. (BOBBIO, 2004, p. 86).

A terceira boa razão é compreendida como um princípio moral absoluto, enquanto reconhecimento dos direitos inalienáveis da natureza humana.

Para além das razões de método, pode-se aduzir em favor da tolerância uma razão moral: o respeito à pessoa alheia. $\mathrm{O}$ reconhecimento do direito de todo homem a crer de acordo com a sua consciência é estreitamente ligado à afirmação dos direitos de liberdade, religiosa e de opinião, que servem como fundamento ao Estado liberal.

O outro deve chegar à verdade por convicção íntima e não por imposição. A tolerância, aqui, não é desejada porque socialmente útil ou politicamente eficaz, mas sim por ser um dever ético. Nesse caso o tolerante não é cético, porque crê em sua verdade. Tampouco é indiferente, porque inspira sua própria ação num dever absoluto, como é o de respeitar a liberdade do outro. (BOBBIO, 2004, p. 87).

Além dessas três doutrinas que consideram a tolerância de um ponto de vista da razão prática, haveria outras que a consideram de um ponto de vista teórico, segundo as quais o alcance da verdade só se torna possível pelo confronto. Tais doutrinas, de acordo com Bobbio, levam em conta que a verdade apresenta muitas faces, sendo a tolerância uma "necessidade inerente à própria natureza da verdade" (Bobbio, 2004, p. 87). A esse respeito o autor destaca:

São pelo menos três as posições filosóficas representativas dessa exigência: o sincretismo, de que foi expressão, na época das grandes controvérsias teológicas, o humanismo cristão, e hoje, numa época de grandes conflitos ideológicos, as várias tentativas de conjugar cristianismo e marxismo; o ecletismo, ou filosofia do "justo meio", que teve o seu breve momento de celebridade como filosofia da restauração, e, portanto, também numa perspectiva irônica, após período de choque violento entre revolução e reação, revivendo hoje nas várias propostas de "terceira via", entre liberalismo e socialismo, entre mundo ocidental e mundo oriental, entre capitalismo e coletivismo; e o historicismo relativista, segundo o qual, para retomar a famosa afirmação de Max Weber, numa era de politeísmo de valores, o único templo aberto deveria ser o Panteão, um templo no qual cada um pode adorar seu próprio deus. (BOBBIO, 2004, p. 88). 


\subsection{Löic Wacquant: Política criminal e tolerância zero}

De um outro ponto de vista mais recente, onde as preocupações se dirigem para as desigualdades urbanas e os processos de penalização podemos citar Loï Wacquant (2001), que em seus estudos sobre o novo estatuto das democracias liberais, apresenta um panorama que reflete a aspiração do novo "senso comum" penal, predominantemente marcado pela criminalização da miséria enquanto complemento da ideologia econômica e social, a qual se encontra fundada no individualismo, em seu aspecto de justiça. Trata-se, na verdade, da doutrina denominada de "tolerância zero", adotada em Nova Iorque na década dos anos 1990 pelo exprefeito Rudolf Giuliani e fundada no princípio de uma ação penal rigorosa e permanente, no sentido de impedir qualquer tipo de infração, por mais simples que ela seja. $O$ objetivo desse rigor penal seria o de garantir a segurança dos cidadãos dos grandes centros urbanos, onde a aplicação da coercibilidade seria a garantia de que todas as transgressões à lei seriam punidas através dos organismos punitivos, administrativos, penais e policiais, os quais passaram a adotar medidas enérgicas para impedir e punir todos os infratores. A partir da aplicação dessa doutrina o que se observou é que foram os despossuídos socialmente os prejudicados, como os negros, os imigrantes, os mais pobres etc., os quais, impossibilitados de recorrer aos meios que garantissem o acesso aos direitos essenciais que foram violados. Dessa forma, essa doutrina, apesar de ter produzidos efeitos satisfatórios em seu processo inicial, apesar de ser uma forma ditatorial e arbitrária de tratar a ordem social em seu nível de intolerância, em sua etapa final apresentou uma série de aspectos negativos, não obstante o fato de ter conquistado espeço no mundo todo, conforme assinala Wacquan:

De Nova Iorque, a doutrina da "tolerância zero", instrumento de legitimação da gestão policial e judiciária da pobreza que incomoda - a que se vê, a que causa incidentes e desordens no espaço público, alimentando, por conseguinte, uma difusa sensação de insegurança, ou simplesmente de incômodo tenaz e de inconveniência -, propagou-se através do globo a uma velocidade alucinante. E com ela a retórica militar da "guerra" ao crime e da "reconquista" do espaço público, que assimila os delinquentes (reais ou imaginários), sem-teto, mendigos e outros marginais a invasores estrangeiros - o que facilita o amálgama com a imigração, sempre rendoso eleitoralmente. (WACQUAN, 2001, p. 30).

Para Wacquant (2001) a recorrência às instituições policial e judiciária se deu na necessidade de uma contenção das desordens gestadas pelo desemprego em massa, pela imposição do trabalho cada vez mais precarizado, assim como pela retração da proteção social.

\subsection{Slavov Zizek: o distanciamento do outro como princípio da tolerância na atualidade}

Complementando essa linha de raciocínio sobre o nível de intolerância nos sistemas liberais democráticos da contemporaneidade, Slavov Zizek (2014) destaca a forma pela qual o poder se manifesta através dos novos mecanismos de controle social. $O$ referido autor faz referência a póspolítica, a qual se constitui como a própria negação aparente das disputas ideológicas, passando a se estabelecer na gestão e administração especializada, enquanto a biopolítica, por sua vez, designa a regulação da segurança e do bem-estar das vidas humanas. Em virtude da despolitização 
da vida, a forma que se torna possível para a mobilização das pessoas se faz através do medo, sendo, justamente por esse motivo que a biopolítica se evidencia como uma política do medo ${ }^{4}$.

Em tempos de predominância de uma tal política, que se orienta pelo medo, Zizek (2014) apresenta um quadro característico da atualidade onde a tolerância passa a coincidir com o seu contrário, ou seja, devemos ser tolerantes com o outro na medida em que efetivamente não devemos nos aproximar demais dele, a ponto de invadir seu espaço. Em outros termos, devemos respeitar a intolerância do outro à nossa proximidade excessiva, daí que a máxima "teme o teu próximo como a ti mesmo", enquanto contraposição a um princípio basilar do cristianismo (ama o teu próximo como a ti mesmo), passa a fundamentar uma forma de comportamento das sociedades capitalistas, no caso o direito de não ser assediado, que reflete o direito de permanecer a uma distância segura dos outros.

Essa nova modalidade de política ocidental, que toma como princípio organizador mobilizador o medo do 'outro', leva em consideração, conforme citado anteriormente, o sujeito que teme algo, procurando evitar aquilo que ele acredita que lhe cause uma ameaça, daí a lógica segundo a qual torna-se necessário criar um distanciamento daquilo que teme, criando-se, em consequência, uma barreira entre si e esse 'outro' como uma forma de proteção e sobrevivência. E é dessa maneira que se torna perceptível o modus operandi do medo de imigrantes (e por extensão, o medo de outros grupos) e a implementação das dificuldades que lhes são impostas na atualidade.

[...] uma vez que o Próximo é originalmente (como Freud suspeitou há muito tempo) uma coisa, um intruso traumático, alguém cujo modo de vida diferente, materializado em suas práticas e ritos sociais) nos perturba, abala o equilíbrio dos trilhos sobre os quais nossa vida corre, quando chega perto demais, esse fato também pode dar origem a uma reação agressiva, visando afastar o intruso incômodo. (ZIZEZ, 2014, p. 58).

\subsection{Jürgen Habermas}

Dentre os teóricos contemporâneos que refletem sobre a tolerância, o pensamento de Jürgen Habermas, sem dúvida que ocupa um lugar de destaque. Apresentando como ponto principal de sua concepção o projeto da modernidade, o referido autor, a partir de sua Teoria da Ação Comunicativa, conforme assinala Freitag (1995, p. 138) "pretendeu desenvolver uma teoria da modernidade calcada em um novo conceito de razão, a razão comunicativa, e em um novo conceito de sociedade, que integrasse o sistema ao mundo vivido". Habermas (2007), considerado por muitos como pensador pertencente à tradição da Escola de Frankfurt e cujo pensamento se encontra, conforme Borradori (2004, p. 57) "centrado sobre a ideia de que a democracia - e a luta pública pela melhor forma de democracia - é a chave para a resolução dos problemas aparentemente insuperáveis". A modernidade apresenta um projeto inacabado e que, portanto, necessita de uma via que possibilite resgatar a razão e integrá-la ao contexto do mundo da vida. E é nesse sentido que Habermas desenvolve suas reflexões buscando diagnosticar e apresentar solução para as patologias da modernidade, em cujo contexto a tolerância se apresenta como uma importante categoria para a reabilitação do projeto moderno. Na perspectiva de Habermas (2007), a tolerância para tal deve expressar "uma razão que reconduza, sem apagar as distâncias, que una sem reduzir o que é distinto ao mesmo denominador, que entre estranhos torne reconhecível o que é comum, mas não deixe ao outro a sua alteridade" (Habermas, 1993, p. 112).

\footnotetext{
${ }^{4}$ A chamada política do medo tem seu surgimento no contexto político das democracias ocidentais, tendo como ponto central os atentados de 11 de setembro, quando o Estado passa a adotar uma postura diferente e não convencional às que vinha tomando em uma realidade de clamor por tolerância e direitos humanos.
} 
A tolerância não se confunde com a virtude do comportamento civil ou com a disposição para cooperar e fazer concessões, em função de seu objeto se referir ao que é inegociável entre as pessoas, a saber, suas visões de mundo, que não podem ser compartilhadas nem conciliadas e, maioria das vezes, conflituosas, as quais determinam as formas de vida que passam a ser assumidas pelos membros de um determinado grupo social.

Na visão do referido autor a tolerância religiosa é compreendida como precursora dos direitos culturais, em função das formas de vida religiosa apresentarem elevado grau de oposição entre as pessoas, pela sua expressão de doutrina abrangente, sendo a tolerância religiosa expressão mais elevada de tolerância política. O Estado deve se comportar de modo a ser intolerante contra seus inimigos, os quais devem ser definidos pelos órgãos do Estado Constitucional.

Fernandes (2017) acrescenta que o fato de Habermas (2007) considerar a tolerância religiosa como precursora de direitos culturais deriva do fato daquele ter estabelecido uma moral da inclusão equitativa, a qual se encontra fundada na não indiferença e na não apreciação das crenças e atitudes alheias, tendo em vista que não existe nada que oponha as pessoas de modo mais substancial do que suas visões de vida religiosa expressada enquanto uma doutrina abrangente. A tolerância religiosa, nessa linha de raciocínio, surge como a forma mais ampla da tolerância política. Em outros termos, qualquer forma de trato social que esteja baseado na tolerância, somente se torna possível na medida em que as pessoas passem a rejeitar mutuamente suas crenças e práticas em função de um conflito cognitivo baseado em "boas razões", os quais somente se tornam efetivos a partir do "uso público da razão".

Através de procedimentos que assegurem a participação dos cidadãos por meio da formação deliberativa da vontade, torna-se possível ao Estado democrático estabelecer a coexistência pacífica entre seus membros com iguais direitos e respeito aos princípios do multiculturalismo.

A imparcialidade dos argumentos reflexivos, tecidos, seja em prol da aceitação, seja a favor da recusa, é assegurada, por meio de um procedimento inclusivo de formação deliberativa da vontade, o qual exige, da parte dos participantes, respeito recíproco, bem como a assunção das perspectivas um do outro. A isso corresponde um mandamento de neutralidade dirigido ao Estado, que passa a oferecer, a seguir, a base normativa para a generalização dos direitos religiosos e culturais. (HABERMAS, 2007, p. 286).

A tolerância na perspectiva de Habermas (2007) não pode ser confundida com a indiferença, tendo em vista que na esfera pública os indivíduos não são percebidos de forma subjetiva, refletindo na mesma o mesmo valor, sendo tolerante aquele que não é preconceituoso ou discriminatório, procurando impor respeito ao outro. Nesse ponto de vista, a tolerância apresenta suas bases constitutivas muito além do ato discriminatório. Um bom exemplo a respeito pode ser encontrado na religião, onde, a partir da eliminação do preconceito existente, torna-se possível a instauração da tolerância.

Habermas (2007) ao analisar o conceito de tolerância moderno, leva em consideração o nível de complexidade e pluralidade das sociedades atuais, nas quais o pluralismo religioso e a forma cada vez mais representativa do caráter político que as tradições religiosas e comunidades de fé passaram a exercer hodiernamente. Nesse sentido a interpretação proposta por Rainer Forst ${ }^{5}$

\footnotetext{
${ }^{5}$ Em Limites da tolerância, Forst desenvolve uma análise a respeito dos aspectos constitutivos do conceito de tolerância, discutindo as duas concepções diferentes do termo, ou seja, como permissão e como respeito moral, os quais expressam diversos modos de demarcar os limites da tolerância. Segundo Forst a tolerância se apresenta como um conceito que, para ganhar determinado conteúdo, depende normativamente de um direito à justificação baseado na ideia do uso público da razão, a partir do qual, as práticas e as instituições político-jurídicas que determinam a vida social dos cidadãos devem ser justificáveis à luz de normas que eles não podem rejeitar de forma recíproca e genérica.
} 
possibilita a Habermas uma compreensão pós-secular da tolerância, que se encontra calcada na formação deliberativa da vontade dos cidadãos, que expressam o desejo de se reconhecerem como iguais em sociedades caracterizadas pelas suas diversidades culturais, elaborando uma apologia da tolerância enquanto princípio de emancipação, possibilitando a garantia dos direitos culturais ${ }^{6}$ a partir da proposta de um agir comunicativo, tornando possível a existência de uma cultura política compartilhada, a qual se manifesta na tolerância que se afigura na integração dos cidadãos do Estado.

Nas discussões concernentes aos problemas existenciais e ético-políticos, surgidos a partir do terrorismo e fundamentalismo, Habermas destaca o valor e a importância da tolerância no contexto mundial da atualidade que se encontra dominada pelas mais variadas formas de violência, as quais nos levam a perceber uma nova forma de barbárie. Para o filósofo a violência que se encontra radicalizada no terrorismo e no fundamentalismo se define como uma patologia comunicativa.

[...] Por outro lado, e por isso, os conflitos surgem da distorção na comunicação, do malentendido e da incompreensão, da insinceridade e da impostura. Quando as consequências desses conflitos se tornam dolorosas o bastante, elas vão parar em um tribunal ou consultório de um terapeuta. A espiral de violência começa como uma espiral de comunicação distorcida que leva, por meio da incontrolável espiral de desconfiança recíproca, à ruptura da comunicação, depois que ela entrou em erupção é possível saber o que não deu certo e o que deve ser consertado. (BORRADORI, 2004, p. 48 - grifos do autor).

Ao se referir a "desconfiança recíproca", o filósofo atenta para as relações predominantes entre as grandes potências ocidentais e as nações pobres do Oriente, cuja resultante se manifesta num plano de relações internacionais e interculturais na forma de uma "espiral de estereótipos" que possibilita compreender a distância cultural e as desigualdades econômicas existentes entre esses dois diferentes modos de vida. É preciso que o Ocidente proceda uma revisão de sua autoimagem para que possa ser reconhecido como capaz de proporcionar um modelo civilizatório.

No processo de revisão de sua autoimagem, o Ocidente poderia aprender, por exemplo, como seria necessário mudar sua política se quiser ser percebido como um poder modelador de impacto civilizacional. Sem a domesticação de um capitalismo irrefreado, a estratificação devastadora da sociedade mundial permanecerá intratável. (Borradori, 2004, p. 48).

\section{A tolerância como consenso e marco normativo internacional no contexto atual}

Criada em 24 de outubro de 1945, durante o período da II Guerra Mundial que arrasou a Europa, a Organização das Nações Unidas (ONU) surgiu da necessidade de se buscar a paz e a tolerância entre as nações. No ano de 1995, quando da comemoração de seu $50^{\circ}$ aniversário de criação, deliberou-se que aquele seria o Ano Internacional da Tolerância, num certo reconhecimento de que mesmo após 50 anos de existência, aquela instituição não havia minimamente atingido os objetivos propostos em suas origens. Naquele momento, inúmeros conflitos deflagrados nos diversos continentes, em sua maioria motivados por intolerância religiosa, étnica e política levaram a constatar que a realização do projeto idealizado pela $\mathrm{ONU}$ estava ainda em seu ponto de partida. Foi nesse sentido que entre o período compreendido nos

\footnotetext{
${ }^{6}$ No entendimento de Habermas, direitos culturais são aqueles capazes de garantir de forma totalizante a inclusão, sendo necessária à sua justificação, levando-se em conta as possibilidades de inclusão simétrica dos cidadãos.
}

SARMENTO, Jorge Alberto Ramos. Os caminhos da tolerância. Griot : Revista de Filosofia, Amargosa - BA, v.21 n.3, p.390-407, outubro, 2021. 
anos de 1994 e 1995 foram realizados, sob os auspícios da UNESCO, uma série de encontros regionais com o propósito de se discutir o conceito de tolerância a partir das diversas realidades locais, dando ensejo à elaboração e aprovação pelos Estados-membros da UNESCO em 16 de novembro de 1995 a Declaração de Princípios sobre a Tolerância ${ }^{7}$ se apresenta como um marco histórico normativo na fundamentação e balizamento de condutas para os indivíduos de todos os países. Tal declaração estabelece em seu primeiro artigo que "a tolerância é o respeito, a aceitação e o apreço da riqueza e da diversidade das culturas de nosso mundo, de nossas maneiras de exprimir nossas qualidades de seres humanos". Afirma ainda que a tolerância não é indulgência e nem indiferença, apontando para a apreciação da rica variedade das culturas do mundo e das mais variadas formas de expressão. Em seu artigo segundo estabelece que no contexto do Estado a tolerância traz como consequência a justiça e a imparcialidade na legislação, na aplicação da lei e no exercício dos poderes judiciário e administrativo, além da exigência de que todos tenham iguais oportunidades para desfrutar de oportunidades econômicas e sociais sem discriminações. Em seu terceiro artigo, que trata das dimensões sociais, chama a atenção para o recrudescimento da intolerância no mundo atual, caracterizado por uma economia global e pela aceleração da mobilidade, da comunicação, da integração, e da interdependência, das migrações e dos deslocamentos das populações, da urbanização e da transformação das formas de organização social, havendo a necessidade de se criarem mecanismos visando combatê-la. No seu quarto artigo é destacada a necessidade da educação como instrumento mais eficaz de prevenir a intolerância, sendo que a primeira etapa dessa educação consiste em ensinar aos indivíduos quais são os seus direitos e suas liberdades, no sentido de assegurar seu respeito assim como de incentivar a vontade de proteger os direitos e liberdades dos outros.

\section{Considerações finais}

Enquanto um conceito fundamental do pensamento político da cultura liberal, a tolerância desde que se tornou uma categoria vinculada a esfera filosófica a partir do século XVI na Europa durante as guerras religiosas, tem sido um elemento importante na reflexão desenvolvida pelos pensadores modernos a começar com Locke para quem a tolerância encontrava-se associada à religião, assim como as contribuições de Voltaire e Kant cujas críticas foram de grande importância para uma melhor compreensão acerca dessa categoria a partir dos séculos seguintes. Na contemporaneidade teóricos como Stuart Mill percebem um atrelamento da tolerância com as ideias de liberdade e justiça, as quais muitas vezes passam a ser definidas erroneamente. Por seu turno, Popper em suas análises epistemológicas percebe que o avanço nas práticas científicas está relacionado com práticas democráticas calcadas na tolerância. Na visão de Wacquant, o novo estatuto das democracias liberais traz consigo a precarização do trabalho e a exclusão social, ensejando novos mecanismos para resguardar a ordem social via formas autoritárias ditatoriais, cujas consequências passam a refletir um nível elevando de intolerância ou da tolerância zero. Em Zizek vemos a formulação de uma concepção que segue de forma similar a linha de raciocínio de Wacquant, segundo a qual assistimos a uma política que se orienta pelo medo e na qual a tolerância passa a coincidir com o seu contrário, fazendo com que a aproximação com o outro exija a não-aproximação dele, respeitando a sua intolerância.

Na concepção desenvolvida por Habermas, a tolerância encontra-se pautada nos ideais políticos e não mais se referindo à questão religiosa, havendo a necessidade de que todos obedeçam determinados princípios republicanos, emanados do direito de todos e não de grupos. A linha de

\footnotetext{
${ }^{7}$ A referida declaração foi o resultante de sete conferências regionais realizadas em vários países.
} 
raciocínio habermasiana encontra-se orientada pela teoria do agir comunicativo como contraposição à racionalidade econômica e burocrática que de forma crescente penetra nas esferas do mundo da vida, tornando-as colonizadas e levando-as à perda de liberdade e sentido.

De maneira geral, as mais diferentes concepções apresentadas pelos diversos pensadores sobre a tolerância, desde Locke até Habermas, enfatizadas neste breve trabalho, parecem apresentam um ponto em comum, que é justamente o fato de que a tolerância seria a aceitação e o reconhecimento de que todos os outros indivíduos têm o mesmo direito de adotarem determinadas visões de mundo, crenças, assim como estilos de vida não necessariamente iguais aqueles que nós adotamos ou mesmo acreditamos que sejam os mais corretos. A esse respeito podemos afirmar que o século XX foi um período marcado pela intolerância, fato que pode ser comprovado pelas guerras (o período em questão começa com duas guerras mundiais) pelas guerras de independências das colônias, pelos genocídios, além das inúmeras crises sociais e humanitárias verificadas em muitos países, a ascensão ao poder de governos ditatoriais, sem citar as crises ambientais oriundas do chamado "progresso científico", que deixou em segundo plano o próprio progresso humano. A Declaração de Princípios sobre a Tolerância, publicada pela UNESCO em 1995, reflete, em última análise os esforços desenvolvidos pela ONU em busca da tão almejada paz entre as nações, propósito que atualmente, para além de qualquer pessimismo, parece cada vez mais distante de ser alcançado. No entanto, enquanto existir uma consciência voltada para a esperança de dias melhores, assim como a necessidade da construção de um mundo mais humano e mais justo, no qual todos possam ter oportunidades e direitos iguais, a tolerância não deixará de ser um importante elemento de reflexão. 


\section{Referências}

ADORNO, Theodor. Educação e emancipação. São Paulo: Paz e Terra, 2011.

BOBBIO, Norberto. A era dos direitos. Rio de Janeiro: Elsevier, 2004.

BORRADORI, G. Filosofia em tempo de terror: diálogos com Jürgen Habermas e Jacques Derrida. Rio de Janeiro: Jorge Zahar Ed., 2004.

FERNANDES, Wescley. Sobre o conceito de tolerância em Habermas. Revista Aufklärung, João Pessoa, v.4, p. 61-86, abril, 2017.

FREITAG, Bárbara. Habermas e a teoria da modernidade. Cadernos CRH, Salvador, $\mathbf{n}^{\circ} 22$, p. 138163. Jan/jun. 1995.

HABERMAS, Jürgen. Passado como futuro. Rio de Janeiro: Tempo Brasileiro, 1993

HABERMAS, Jürgen. Entre naturalismo e religião: estudos filosóficos. Rio de Janeiro: Tempo Brasileiro, 2007.

LOCKE, John. Carta acerca da tolerância. São Paulo: Abril Cultural (Os pensadores), 1983.

KANT, Immanuel. A paz perpetua e outros opúsculos. Lisboa: Edições 70, 2018.

KANT, Immanuel. Ideia de uma história universal com um propósito cosmopolita. Lisboa: Edições 70, 1990.

KANT, Immanuel. Das diferentes raças humanas. Tradução e notas de Alexandre Hahn. (disponível em:

Http://Www.Academia.Edu/3221053/Das_Diferentes_Raças_Humanas_Immanuel_Kant, acesso em 16/02/2020.

KLEIN, J. Liberdade e religião: reflexões kantianas. Revista ethic@- Florianopolis, SC, v. 14, nº 2 p. 222 - 251, dezembro, 2015.

MILL, John Stuart. A liberdade/Utilitarismo. São Paulo: Martins Fontes, 2000.

POPPER, Karl. A sociedade aberta e seus inimigos. São Paulo: Edusp, 1974.

POPPER, Karl. Em busca de um mundo melhor. São Paulo: Martins Fontes, 2006.

POPPER, Karl. Después de la sociedad aberta: escritos sociales y políticos escogidos. Barcelona: Ed.

Paidós, 2014.

VOLTAIRE. Dicionário filosófico. São Paulo: Abril Cultural, 1984 (Os Pensadores).

VOLTAIRE. Tratado sobre a tolerância. São Paulo: Martins Fontes, 2000.

WACQUANT, Löic. As prisões da miséria. Rio de Janeiro: Jorge Zahar Ed., 2001.

ZIZEK. Slavov. Violência: seis reflexões laterais. São Paulo: Boitempo, 2014.

Autor(a) para correspondência / Corresponding author: Jorge Alberto Ramos Sarmento. jars@ufpa.br

SARMENTO, Jorge Alberto Ramos. Os caminhos da tolerância. Griot : Revista de Filosofia, Amargosa - BA, v.21 n.3, p.390-407, outubro, 2021. 